\title{
Systematic review and meta-analysis on laparoscopic cystectomy in bladder cancer
}

\author{
Jialiang Zhu, Ziwen Lu, Wanbo Chen, Mang Ke, Xianguo Cai \\ Department of Urology, Taizhou Hospital of Zhejiang Province Affiliated to Wenzhou Medical University, Taizhou, China \\ Contributions: (I) Conception and design: J Zhu, X Cai; (II) Administrative support: Z Lu; (III) Provision of study materials or patients: J Zhu, Z \\ Lu, W Chen, M Ke; (IV) Collection and assembly of data: All authors; (V) Data analysis and interpretation: J Zhu, W Chen, M Ke, X Cai; (VI) \\ Manuscript writing: All authors; (VII) Final approval of manuscript: All authors. \\ Correspondence to: Xianguo Cai. No.150 Ximen Street, Linhai City, Taizhou, China. Email: mccaixianguo@126.com.
}

\begin{abstract}
Background: This study aimed to systematically evaluate the efficacy of laparoscopic radical cystectomy (LRC) surgical therapy in patients with bladder cancer (BC), and to provide evidence for the clinical treatment of BC.

Methods: The Embase, Ovid, PubMed, Medline, Springer, and Web of Sciences database were searched to screen articles with clinical controlled trials on LRC treatment of BC. The Cochrane Handbook 5.0.2 software and Review Manager 5.3 software were adopted to evaluate the risk of bias and to perform a meta-analysis of the included articles in this study.

Results: A total of 12 articles were obtained, including 1,283 research cases. The meta-analysis results showed that relative to the control group (Ctrl), the observation group (Observ group) had significantly lower intraoperative blood loss (IBL) after LRC [mean difference (MD) $=-458.75 ; 95 \%$ confidential interval (CI): -505.75 to $-411.76 ; Z=19.13 ; \mathrm{P}<0.00001$ ], blood transfusion rate (BTR) (odds ratio $=0.36$; $95 \%$ CI: 0.13-0.94; $\mathrm{Z}=2.08$; and $\mathrm{P}=0.04$ ), use of analgesics ( $\mathrm{MD}=-24.53 ; 95 \% \mathrm{CI}$ : -39.04 to $-10.01 ; \mathrm{Z}=3.31$; and $\mathrm{P}=0.0009$ ), and incidence of postoperative complications (Risk ratio $=0.58 ; 95 \% \mathrm{CI}: 0.39-0.85 ; \mathrm{Z}=2.77$; and $\mathrm{P}=0.006)$. However, and the length of hospital stay could not be shortened (MD $=-2.43 ; 95 \% \mathrm{CI}:-4.83$ to $-0.02 ; \mathrm{Z}=1.98$; and $\mathrm{P}=0.05)$.

Discussion: LRC treatment of BC could effectively reduce the amount of IBS, and lower the intraoperative BTR, use of analgesics, and incidence of postoperative complications. Therefore, it could be used in the clinical surgical treatment of $\mathrm{BC}$ patients.
\end{abstract}

Keywords: Bladder cancer (BC); laparoscopic radical cystectomy (LRC); meta-analysis; treatment effect

Submitted Nov 08, 2021. Accepted for publication Dec 24, 2021.

doi: $10.21037 /$ tau-21-1076

View this article at: https://dx.doi.org/10.21037/tau-21-1076

\section{Introduction}

Bladder cancer (BC) is one of the most common malignant tumors of the genitourinary system and the seventh most diagnosed malignant tumor among men, resulting in a significant impact on the psychology, lives, and health of patients (1). According to statistics, there are 420,000 new cases of BC. Among them, the death cases are about 160,000, the incidence of developed countries such as Europe and North America is high, BC is the seventh of male cancer, and the tenth of female cancer (2). The incidence of bladder cancer in China is $7.49 / 100,000$, accounting for $2.50 \%$ of China's malignant tumors (3). The current research shows that occupational exposure, overweight/obesity, smoking, and improper eating habits are risk factors (4). Generally speaking, smoking, unreasonable diet, and lack of drinking water are all pathogenic factors. In daily life, a person who does not like drinking water or drinking less cannot guarantee the quality of the body's metabolism, and the risk of $\mathrm{BC}$ is very high in these individuals. Globally, the 
death rate of $\mathrm{BC}$ ranks ninth, and its incidence and death rates are increasing. In terms of the upward trend, men are higher than women, and developed areas are higher than poor areas (5). Previous studies have shown that smoking and occupational exposure are the two major risk factors for $\mathrm{BC}$, with about $30-50 \%$ of $\mathrm{BC}$ cases caused by smoking. For patients diagnosed with $\mathrm{BC}$ that continue to engage in excessive smoking, it will further aggravate the disease and seriously affect the patient's life. Long-term exposure to industrial chemicals (such as paint and rubber) during work, and family factors are also important factors for $\mathrm{BC}$, with occupational factor-induced $\mathrm{BC}$ accounting for approximately $20 \%$ of all cases (6). In addition to these two high-risk factors, chronic schistosome infections, sex hormones, and genetic factors may all lead to BC (7). Compared to other malignant tumors, $\mathrm{BC}$ has relatively good prognosis, and regular physical examination is helpful for early BC diagnosis.

Hematuria is the most common symptom of patients with $\mathrm{BC}$, which can be divided into two types: microscopic hematuria and gross hematuria. There are many histological types of $\mathrm{BC}$, and can be divided into urothelial carcinoma, squamous cell carcinoma, and adenocellular carcinoma according to the pathological type, the incidence rates of which were over $90 \%, 3-7 \%$, and $<2 \%$, respectively $(8,9)$. According to the depth of invasion, $\mathrm{BC}$ can be classified into muscle-invasive BC (MIBC) and non-muscle-invasive BC (NMIBC). Studies have shown that NMIBC accounts for approximately $75 \%$ of the all BC cases, and about $40 \%$ of patients will eventually progress from NMIBC to MIBC (10). MIBC has a low incidence; however, it is an aggressive malignant tumor with a high tendency to metastasize, with a poor prognosis and high fatality rate. The 5 -year survival rate of patients who develop lymph node metastasis is only $15-30 \%$ (11). At present, the treatment of bladder cancer mainly includes: radical perfectly, transurethral bladder tumor electrical cutting (TUR-BL), transurethral laser surgery, and photodynamic treatment, etc. (12). The most effective treatment method for MIBC is laparoscopic radical cystectomy (LRC). Pelvic lymph node dissection (PLND) is required when radical cystectomy (RC) is performed on MIBC patients, and therefore, RC combined with PLND is the gold standard for treatment of MIBC (13). When LRC is performed on MIBC patients, the scope of surgery will vary depending on the body structures of men and women. The resection scope of male MIBC patients should include the bladder, surrounding fat tissue, distal ureter, prostate, and seminal vesicles. For female MIBC patients, the bladder, surrounding adipose tissue, distal ureter, uterus, and part of the anterior vaginal wall have to be excised. If the $\mathrm{BC}$ is found to have invaded the urethra, a combined total urethral resection is required intraoperatively $(14,15)$.

RC includes LRC and open RC (ORC). ORC has a definite curative effect and is the gold standard surgery for MIBC. However, ORC involves significant trauma, heavy bleeding, slow postoperative recovery, as well as an increased risk of postoperative complications in patients (16). With the continuous advancement of medical technology, LRC has gradually replaced ORC as the first choice for the clinical treatment of MIBC. LRC can fully expose the surgical field of view, improve surgical accuracy, and reduce intraoperative blood loss (IBL) and blood transfusion rate (BTR). In addition, it is minimally invasive, which reduces the incidence of postoperative complications to a certain extent, and shortens the length of hospital stay $(17,18)$. Although LRC has achieved definite treatment effects in MIBC surgical treatment, there remains some controversy with ORC treatment methods. Moreover, the current literature on LRC treatment of MIBC lacks a unified evaluation standard for surgical efficacy, making it difficult to objectively and accurately reflect the treatment effect of LRC on BC patients. Aboumarzouk et al. (19) used metaanalysis to compare the effects of LRC and ORC in the treatment of BC, but the number of total cases is only 427 . Therefore, this research is to further incorporate results in recent years, increase the number of patients incorporating patients, perform a meta-analysis to systematically evaluate articles reporting on LRC treatment of BC, with the aim of providing a theoretical basis for the clinical selection of reasonable MIBC treatment. We present the following article in accordance with the PRISMA reporting checklist (available at https://tau.amegroups.com/article/ view/10.21037/tau-21-1076/rc).

\section{Methods}

\section{Article retrieval}

Articles involving clinical controlled trials on LRC treatment of BC were searched from six English databases (Embase, Ovid, PubMed, Medline, Springer, and Web of Sciences) from the date of establishment of the database to March 1, 2021. The search language was English, and the search was performed by stochastic combination of topic words and free terms. The English retrieval terms were composed of "BC", "muscle-invasive BC", "non-muscle-invasive BC", "radical 
cystectomy", "laparoscopic radical cystectomy", "open radical cystectomy", "MIBC", "NMIBC", "RC", "LRC”, and "ORC". The search words were combined with "and" or "or". The literature search was conducted by two researchers using independent search methods.

\section{Literature inclusion and exclusion criteria}

The inclusion criteria were as follows: (I) articles whose subjects were diagnosed with $\mathrm{BC}$ through preoperative examination or clinical pathology, and aged $\geq 18$ years old; (II) clinical case-control trials published in English in a foreign English database; (III) studies that adopted LRC in the observation (Observ) group and non-LRC in the control (Ctrl) group, and baseline data of the patients in both groups were comparable; (IV) studies involving research objects that had no history of gastrointestinal surgery and could undergo radical total cystectomy; and (V) articles including the following evaluation indicators: operation time, IBL, incidence of postoperative complications, and postoperative length of hospital stay.

The exclusion criteria were as follows: (I) article involving research objects who suffered from non-BC and those with animal or cell research objects; (II) unpublished articles such as degree theses, reviews, special case reports, or non-English literature; (III) studies with LRC combined with other methods for the Observ group; (IV) the research objects were BC, and also suffers from other diseases; and (V) studies with incomplete, ineffective, or unrelated data indicators.

\section{Article screening}

Following the literature retrieval process, the titles of all the retrieved articles were entered into NoteExpress 3.2 software (Beijing Aegean Music Technology Co., Ltd.) to establish a document database, and were then de-duplicated using the NoteExpress 3.2 software. Subsequently, two literature researchers were invited to independently screen the articles. Firstly, they conducted a preliminary screening by reading the titles and abstracts of the articles to determine whether they were relevant to the meta-analysis, and to delete articles that did not meet the inclusion criteria. Next, the full texts of the articles were read to determine whether they should be included, based on the inclusion and exclusion criteria. If the data in the article was not clearly described, we attempted to contact the author to obtain detailed information. If the detailed data was not available, it would be directly excluded. In the literature screening process, disagreements between the two researchers were resolved by discussion, and if a consensus could not be reached, a third researcher was asked to arbitrate. After the articles were screened, those meeting the requirements were sorted.

\section{Data extraction}

Two researchers extracted the data independently. Next, an Excel table (Microsoft, Washington, America) was created based on the basic information of the article, the characteristics of the research objects, intervention measures, outcome indicators, and bias evaluation, etc. The extracted data was then crosschecked. Any disagreements between the two researchers during the data extraction process were resolved through discussion or arbitration by a third researcher. In this study, the extracted data consisted of the basic information of the article (document title, first author, publication year, author information, and document source, etc.), basic characteristics of the study subjects (gender, age, research sample size, and baseline comparability, etc.), research methods, research plan design, intervention measures in the two groups, outcome evaluation indicators, and outcome data. It compared the efficacy of two groups, including blood loss, blood transfusion rate, analgesic use, postoperative complications, and hospital stay.

\section{Bias risk assessment}

The Cochrane Handbook (version 5.0.2) systematic review writing manual was adopted to assess the bias risk of the included articles. The content of the bias risk assessment of the systematic review writing manual included the following items: (I) random sequence (whether a random number table or other methods were used to randomize the research subjects); (II) allocation concealment (whether the groups were random and the subjects were kept confidential); (III) blinding of research subjects (whether the clinical research subjects know about the experiment process and grouping); (IV) blinding of outcome reviewers (whether the researchers or outcome assessors knew the subject's groups and the interventions received); (V) complete or missing data; (VI) whether the study had selective reporting; and (VII) whether there were other biases. Regarding the above 7 items, "satisfaction" indicated that the bias was relatively small, and "do not satisfy" referred to highly bias, the study 
did not have sufficient detailed report, if not mentioned, danger was unknown assessment including random sequence generation, allocation, blind method, and tracking/exiting four dimensions, which were 1 to 3 points, regarded as low quality, 4 to 7 points were considered high quality. In the assessment on risk bias and analysis of the included article, if there was any disagreement between two researchers during the data extraction process, it could be solved by friendly discussion or solicited by a third researcher.

\section{Statistical analysis}

STATA11.0 software (StataCorp, America), Cochrane Handbook 5.0.2 software, and Review Manager5.3 software (cochrane collaboration network) were adopted to merge the statistics of the included articles, evaluate risk of bias of the included articles, and perform meta-analysis of the combined statistics. Forest diagrams and funnel diagrams were then drawn on the basis of the analysis results. For meta-analysis, the articles were examined for heterogeneity using the $\mathrm{I}^{2}$ test to observe whether the studies could be combined, and the $\mathrm{P}$ value was undertaken as an index to evaluate the heterogeneity. If the result of the heterogeneity test showed that $\mathrm{I}^{2} \geq 50$ and $\mathrm{P}<0.05$, this suggested that the heterogeneity among studies was small, and the fixed effects model (FEM) could be adopted for meta-analysis of the combined effect size. However, if the result showed that $\mathrm{I}^{2}<50$ and $\mathrm{P}>0.05$, this indicated that there was heterogeneity among the studies, so the random effects model (REM) could be applied for meta-analysis. The relative risk (RR) was applied as the effect scale indicator for intraoperative BTR, incidence of postoperative complications, and other binary variables, and the $95 \%$ confidence interval ( $95 \% \mathrm{CI})$ was calculated. The weighted mean difference (WMD) was applied as the effect scale index for continuous variables such as operation time, IBL, length of hospital stay, and use of analgesics, and the 95\% CI was calculated. The u-test was utilized to determine whether there was statistical meaning between the combined effect sizes, and the probability $\mathrm{P}$ value was calculated based on the $u$ value. $\alpha=0.05$ was used as the test level, and $\mathrm{P}<0.05$ indicated that the difference was statistically significant.

\section{Results}

\section{Literature retrieval results}

Clinical controlled studies of LRC treatment of BC were searched in six English databases from the date of establishment of the database to March 1, 2021. A total of 1,326 related articles were obtained after the preliminary search, among which 388 related articles were retrieved from the PubMed database, 232 from Embase, 249 from Medline, 206 from Springer, 108 from Ovid, and 143 from Web of Sciences. After the preliminary search, the references of the retrieved articles were entered into NoteExpress 3.2 software to eliminate the duplicate documents, leaving 901 articles. After the titles and abstracts of the article were read, 619 articles that were obviously inconsistent with the subject of this study were excluded. Finally, the content of the articles was read carefully to strictly screen based on the inclusion and exclusion criteria. In total, 12 articles (20-31) were included, which were all publicly published clinical controlled studies. The publication time was from 2004 to 2021 . These studies involved 1,239 subjects, including 607 cases in the Observ group and 632 cases in the Ctrl group, and the baseline data of the two groups were comparable. The specific process of literature retrieval is presented in Figure 1, and the basic data of the included articles is shown in Table 1.

\section{Assessment on bias risk of included articles}

The Cochrane Handbook (version 5.0.2) systematic review writing manual was adopted to assess the bias risk of the 12 included articles, and the Review Manager5.3 software was applied to construct the bias risk chart (Figures 2,3). The risk of bias assessment included the following: (I) random sequence (eight articles reported random grouping and were thus considered "low risk", one article did not report whether random grouping was applied, and was considered "unclear risk", and three articles clearly mentioned that the grouping method was "non-random", indicating that these articles were "high risk"); (II) allocation concealment (two articles mentioned allocation concealment, suggesting that they were "low risk", while 11 articles did not mention allocation concealment, indicating they were "unclear risk"); (III) subject blinding (two articles mentioned that the patients were informed, indicating "high risk", while 10 articles did not mention such information, indicating that they were "unclear risk"); (IV) blinding of outcome assessor (three articles mentioned blinding the outcome assessor, suggesting they were "low risk", while nine articles did not mention such information, suggesting they were "unclear risk"); (V) data completion (all 12 articles had complete data, indicating "low risk"); (VI) selective reporting (there 


\section{Identification of studies via databases and registers}

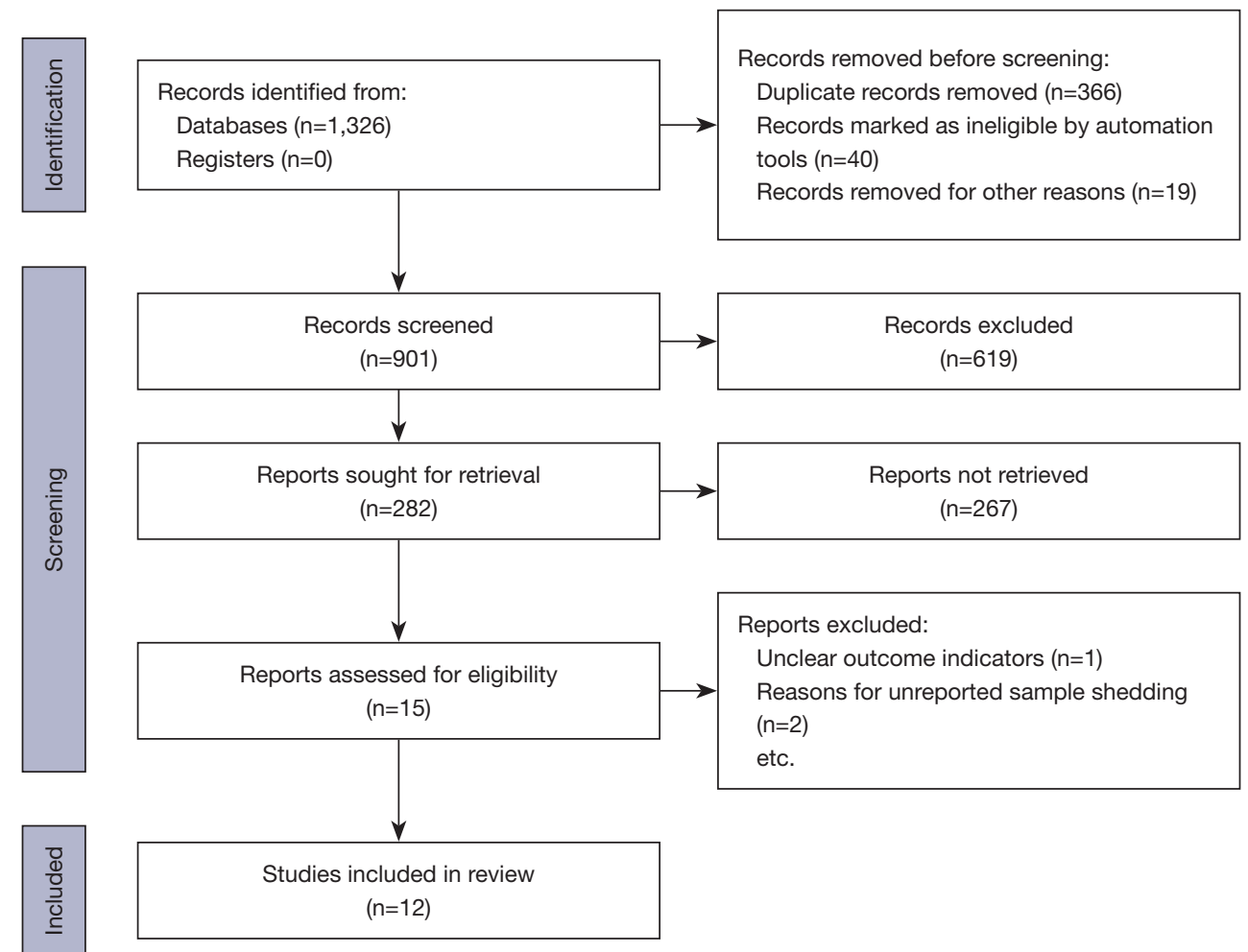

Figure 1 Literature retrieval process.

was no selective reporting in the 12 articles, indicating "low risk"); and (VII) other biases (the other biases of all 12 articles were impossible to evaluate, so they were all considered as "unclear risk").

\section{Operation time}

Ten of the 12 included articles included reported on the operation time of the LRC and ORC groups. A total of 999 patients with BC were included, of which 486 were in the LRC group and 513 were in the ORC group. The heterogeneity test results $\left(\mathrm{I}^{2}=83 \%\right.$ and $\left.\mathrm{P}<0.00001\right)$ revealed that there was a certain degree of heterogeneity among the studies, so the data were analyzed with the REM, and the analysis results are illustrated in Figure 4. The interval of combined effect size of the meta-analysis [mean difference $(M D)=63.35 ; 95 \%$ CI: 41.83-84.87; $Z=5.77$; and $\mathrm{P}<0.00001]$ was on the right side of the invalid line, indicating that operation time of the LRC group was markedly superior to that of the ORC group.
IBL

Five articles $(21-23,25,27)$ reported on IBL in the LRC and ORC groups. A total of 370 patients with BC were included, with 178 cases in the LRC group and 192 in the ORC group. The heterogeneity test result $\left(\mathrm{I}^{2}=0 \%\right.$ and $\left.\mathrm{P}=0.78\right)$ confirmed that the homogeneity among the studies was relatively good, so the FEM was used to analyze the research data. According to the analysis results (Figure 5), the interval of combined effect size of the meta-analysis ( $M D=-458.75 ; 95 \% \mathrm{CI}$ : -505.75 to $-411.76 ; \mathrm{Z}=19.13$; and $\mathrm{P}<0.00001$ ) was on the left side of the invalid line, suggesting that the IBL the LRC group was significantly inferior to that of the ORC group.

\section{Intraoperative blood transfusion rate}

Three articles $(22,27,28)$ reported on intraoperative BTR in the LRC and ORC groups. A total of 281 patients with BC were included, with 153 cases in the LRC group and 128 in the ORC group. The heterogeneity test results $\left(\mathrm{I}^{2}=60 \%\right.$, 
Table 1 Basic data of included articles

\begin{tabular}{|c|c|c|c|c|c|}
\hline First author & Published year & Group & Sample size & Gender (male/female) & Surgical approach \\
\hline \multirow[t]{2}{*}{ Basillote JB } & 2004 & Observ & 13 & $13 / 0$ & LRC \\
\hline & & Ctrl & 11 & $11 / 0$ & ORC \\
\hline \multirow[t]{2}{*}{ Hemal AK } & 2007 & Observ & 30 & $28 / 2$ & LRC \\
\hline & & Ctrl & 35 & $33 / 2$ & ORC \\
\hline \multirow[t]{2}{*}{ Guillotreau J } & 2009 & Observ & 38 & $36 / 2$ & LRC \\
\hline & & Ctrl & 30 & $25 / 5$ & ORC \\
\hline \multirow[t]{2}{*}{ Ha US } & 2010 & Observ & 36 & $32 / 4$ & LRC \\
\hline & & Ctrl & 34 & $27 / 7$ & ORC \\
\hline \multirow[t]{2}{*}{ Pruthi RS } & 2010 & Observ & 10 & l & LRC \\
\hline & & Ctrl & 20 & I & ORC \\
\hline \multirow[t]{2}{*}{ Zheng W } & 2012 & Observ & 45 & $39 / 6$ & LRC \\
\hline & & Ctrl & 65 & $54 / 11$ & ORC \\
\hline \multirow[t]{2}{*}{ Pyun JH } & 2016 & Observ & 26 & $24 / 2$ & LRC \\
\hline & & Ctrl & 38 & $35 / 3$ & ORC \\
\hline \multirow[t]{2}{*}{ Yong C } & 2017 & Observ & 29 & $20 / 9$ & LRC \\
\hline & & Ctrl & 28 & $19 / 9$ & ORC \\
\hline \multirow[t]{2}{*}{ Esquinas $\mathrm{C}$} & 2018 & Observ & 86 & l & LRC \\
\hline & & Ctrl & 70 & I & ORC \\
\hline \multirow[t]{2}{*}{ Lenfant L } & 2018 & Observ & 28 & $26 / 2$ & LRC \\
\hline & & Ctrl & 35 & $22 / 13$ & ORC \\
\hline \multirow[t]{2}{*}{ Subirá-Ríos D } & 2019 & Observ & 108 & $94 / 14$ & LRC \\
\hline & & Ctrl & 108 & $96 / 12$ & ORC \\
\hline \multirow[t]{2}{*}{ Huang $\mathrm{H}$} & 2021 & Observ & 158 & $142 / 16$ & LRC \\
\hline & & Ctrl & 158 & $139 / 19$ & ORC \\
\hline
\end{tabular}

LRC, laparoscopic radical cystectomy; ORC, open radical cystectomy.

and $\mathrm{P}=0.08$ ) indicated that there was heterogeneity among the studies, and therefore, the research data were analyzed using the REM. Figure 6 shows the analysis results. The interval of combined effect size of the meta-analysis [odds ratio $(\mathrm{OR})=0.36$; 95\% CI: $0.13-0.94 ; \mathrm{Z}=2.08$; and $\mathrm{P}=0.04]$ was on the left side of the invalid line. This suggested that the intraoperative BTR of the LRC group was considerably lower than that of the ORC group.

\section{Use of analgesics}

Four articles (20-23) reported on the utilization of analgesics in the LRC and ORC groups. A total of 227 patients were included, with 117 cases in the LRC group and 110 in the ORC group. The heterogeneity test results $\left(\mathrm{I}^{2}=81 \%\right.$, and $\left.\mathrm{P}=0.001\right)$ showed there was a certain degree of heterogeneity among the studies. Therefore, the research data were analyzed by the REM, and the analysis results are presented in Figure 7. The interval of the combined effect of meta-analysis ( $M D=-24.53 ; 95 \%$ CI: -39.04 to $-10.01 ; Z=3.31$; and $P=0.0009)$ was on the left side of the invalid line, which indicated that the adoption of analgesics in the LRC group was obviously inferior to that in the ORC group. 


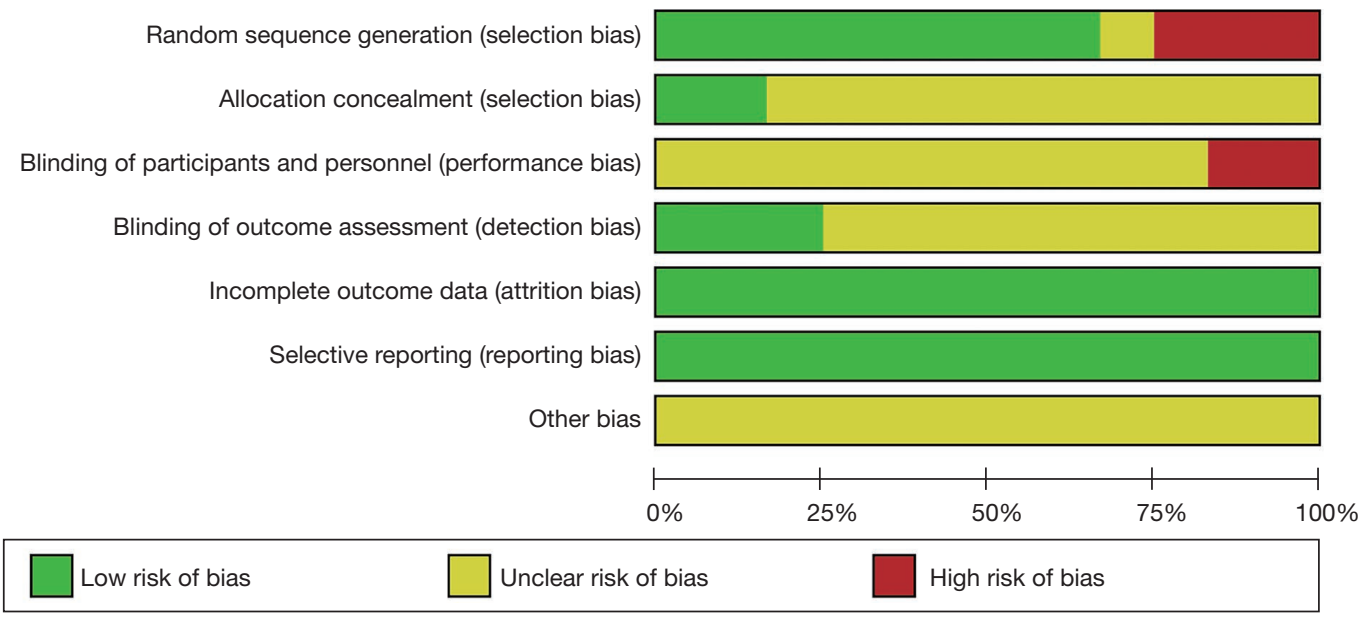

Figure 2 Bar chart for bias risk assessment.

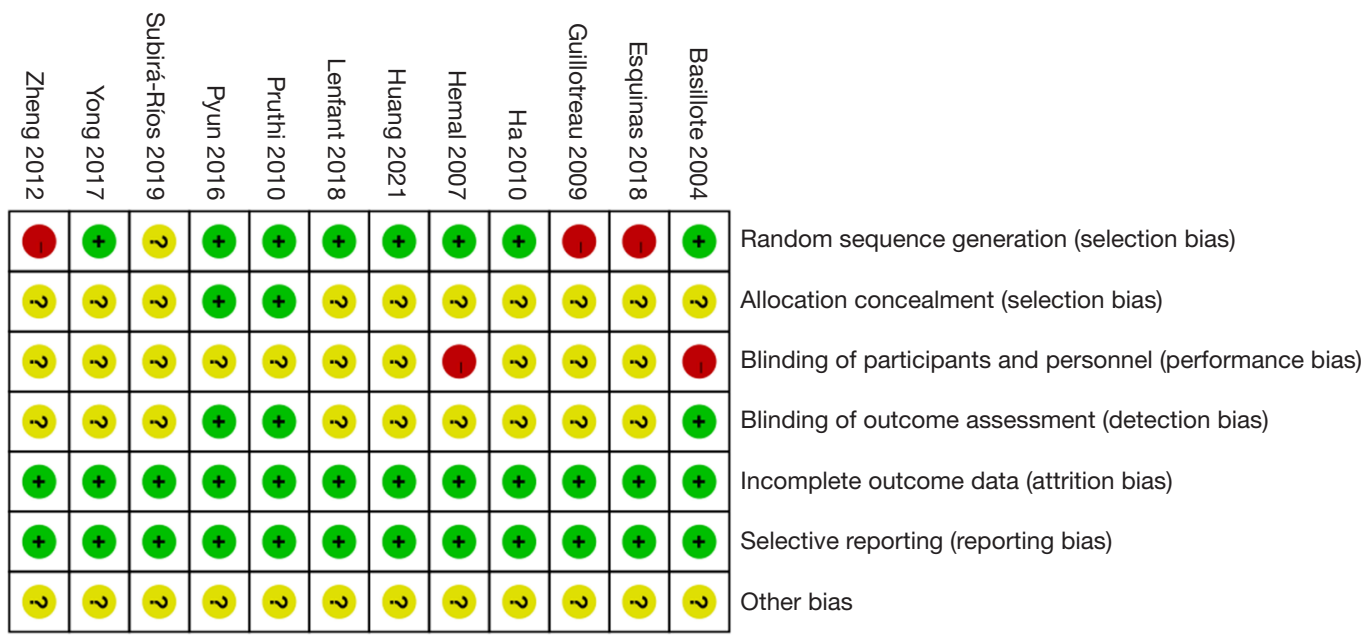

Figure 3 Bias risk evaluation results.

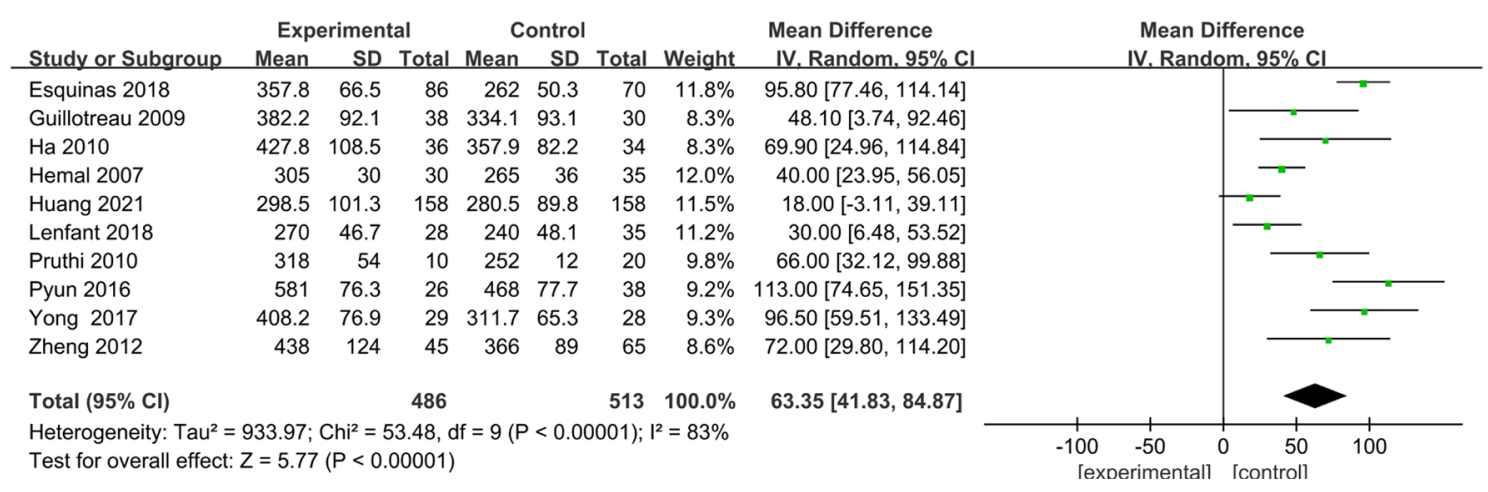

Figure 4 Forest map of the operation time of patients in the two groups. 


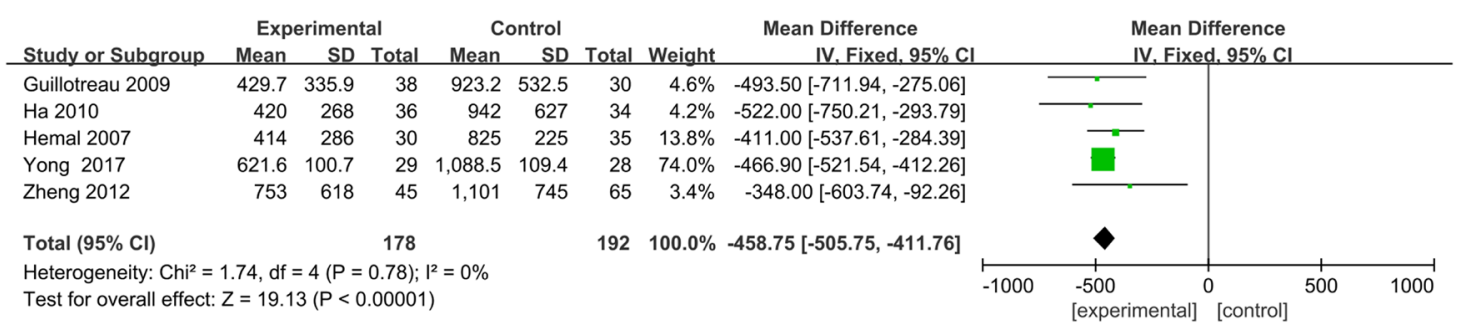

Figure 5 Forest map of intraoperative blood loss of patients in both groups.

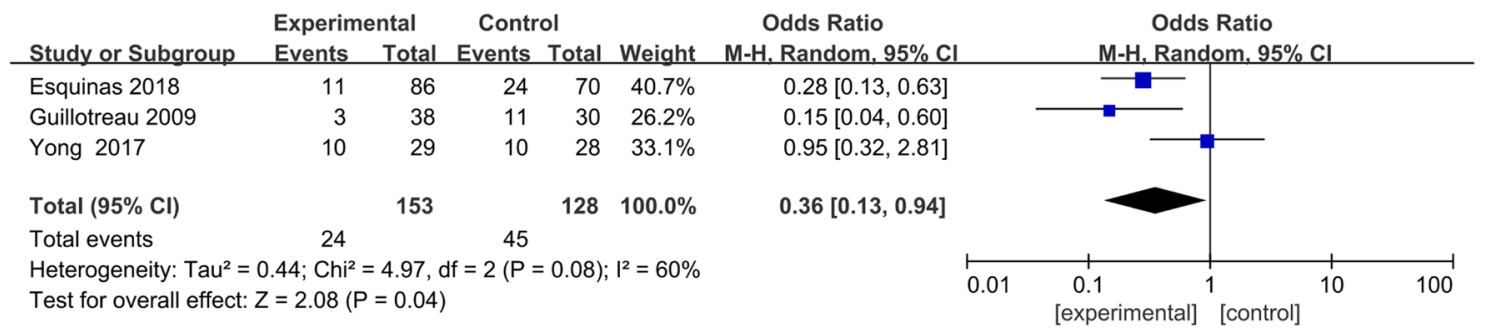

Figure 6 Forest map of blood transfusion rate for patients in both groups.

\begin{tabular}{|c|c|c|c|c|c|c|c|c|c|c|c|}
\hline \multirow[b]{2}{*}{ Study or Subgroup } & \multicolumn{3}{|c|}{ Experimental } & \multicolumn{2}{|c|}{ Control } & \multirow[b]{2}{*}{ Total } & \multirow[b]{2}{*}{ Weight } & \multirow{2}{*}{$\begin{array}{l}\text { Mean Difference } \\
\text { IV. Random, } 95 \% \mathrm{Cl}\end{array}$} & \multirow{2}{*}{\multicolumn{2}{|c|}{$\begin{array}{c}\text { Mean Difference } \\
\text { IV. Random, } 95 \% \mathrm{CI}\end{array}$}} & \\
\hline & Mean & SD & Total & Mean & SD & & & & & & \\
\hline Basillote 2004 & 60.7 & 21.9 & 13 & 143.5 & 111.7 & 11 & $4.2 \%$ & $-82.80[-149.87,-15.73]$ & & & \\
\hline Guillotreau 2009 & 21.2 & 20.6 & 38 & 41.5 & 35.8 & 30 & $27.6 \%$ & $-20.30[-34.69,-5.91]$ & $=$ & & \\
\hline Ha 2010 & 26.4 & 9.6 & 36 & 39.4 & 16.4 & 34 & $35.2 \%$ & $-13.00[-19.34,-6.66]$ & $\square$ & & \\
\hline Hemal 2007 & 32 & 20 & 30 & 65 & 16.2 & 35 & $33.0 \%$ & $-33.00[-41.95,-24.05]$ & $\square$ & & \\
\hline Total $(95 \% \mathrm{Cl})$ & & & 117 & & & 110 & $100.0 \%$ & $-24.53[-39.04,-10.01]$ & $\vartheta$ & & \\
\hline $\begin{array}{l}\text { Heterogeneity: } \mathrm{Tau}^{2}= \\
\text { Test for overall effect: }\end{array}$ & $\begin{array}{l}145.14 \\
Z=3.31\end{array}$ & $\begin{array}{l}\mathrm{Chi}^{2}= \\
(\mathrm{P}=0 .\end{array}$ & $\begin{array}{l}\text { 16.16, } \\
.0009)\end{array}$ & $d f=3($ & $=0.00$ & 1); $\left.\right|^{2}=$ & $81 \%$ & & $\begin{array}{ccc}-200 & -100 & 0 \\
\text { [experimental] }\end{array}$ & $\begin{array}{l}0 \\
\text { [control] }\end{array}$ & 200 \\
\hline
\end{tabular}

Figure 7 Forest map of analgesics adoption for patients in both groups.

\section{Length of hospital stay}

Five articles $(21-23,25,28)$ reported on the length of postoperative hospital stay in the LRC and ORC surgery groups. A total of 469 patients were included, with 235 cases in the LRC group and 234 in the ORC group. There was a certain degree of heterogeneity $\left(\mathrm{I}^{2}=57 \%\right.$, and $\left.\mathrm{P}=0.06\right)$ among the studies, and therefore, the REM was adopted to analyze the research data (Figure 8). The interval of combined result of the effect size of meta-analysis (MD $=-2.43 ; 95 \%$ CI: -4.83 to $-0.02 ; \mathrm{Z}=1.98$; and $\mathrm{P}=0.05$ ) intersected the invalid line, indicating that the length of hospital-stay of the two groups of patients showed no statistically significant distinction.

\section{Incidence of postoperative complications}

Six articles $(21,22,25,27,28,30)$, reported the incidence of postoperative complications in the LRC and ORC surgery groups. A total of 672 patients were included, with 336 cases in the LRC group and 336 in the ORC group. The heterogeneity test results $\left(\mathrm{I}^{2}=77 \%\right.$, and $\left.\mathrm{P}=0.0006\right)$ reflected that heterogeneity could be found among the studies, so the REM was utilized. The data analysis results are displayed in Figure 9. The interval of combined effect of meta-analysis (OR $=0.58 ; 95 \%$ CI: $0.39-0.85 ; Z=2.77$; and $\mathrm{P}=0.006)$ was on the left side of the invalid line. Therefore, there was a significantly different between the two groups in the incidence of postoperative complications; that is, the incidence of postoperative complications in the LRC group was significantly lower than that in the ORC group.

\section{Publication bias}

To analyze the publication bias, a funnel chart of various outcome indicators in LRC treatment of BC was drawn 


\begin{tabular}{|c|c|c|c|c|c|c|c|c|c|}
\hline \multirow[b]{2}{*}{ Study or Subgroup } & \multicolumn{3}{|c|}{ Experimental } & \multicolumn{2}{|c|}{ Control } & \multirow[b]{2}{*}{ Total } & \multirow[b]{2}{*}{ Weight } & \multirow{2}{*}{$\begin{array}{l}\text { Mean Difference } \\
\text { IV. Random. } 95 \% \mathrm{CI}\end{array}$} & \multirow{2}{*}{$\begin{array}{c}\text { Mean Difference } \\
\text { IV. Random. } 95 \% \mathrm{Cl}\end{array}$} \\
\hline & Mean & SD & Total & Mean & SD & & & & \\
\hline Esquinas 2018 & 13.6 & 10.1 & 86 & 16.9 & 14.2 & 70 & $18.3 \%$ & $-3.30[-7.25,0.65]$ & - \\
\hline Guillotreau 2009 & 12.7 & 4.1 & 38 & 15.6 & 6.1 & 30 & $25.7 \%$ & $-2.90[-5.44,-0.36]$ & - \\
\hline Ha 2010 & 10.9 & 6.2 & 36 & 17 & 11.6 & 34 & $16.4 \%$ & $-6.10[-10.49,-1.71]$ & 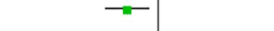 \\
\hline Hemal 2007 & 9.2 & 6.4 & 30 & 11.8 & 6.2 & 35 & $22.7 \%$ & $-2.60[-5.68,0.48]$ & $-{ }_{-1}$ \\
\hline Zheng 2012 & 16.7 & 12.5 & 45 & 13.7 & 9 & 65 & $16.9 \%$ & $3.00[-1.26,7.26]$ & $-\pi$ \\
\hline Total $(95 \% \mathrm{Cl})$ & & & 235 & & & 234 & $100.0 \%$ & $-2.43[-4.83,-0.02]$ & \\
\hline $\begin{array}{l}\text { Heterogeneity: } \mathrm{Tau}^{2}= \\
\text { Test for overall effect: }\end{array}$ & $\begin{array}{l}4.17 ; \mathrm{Cr} \\
z=1.98\end{array}$ & $\begin{array}{l}\mathrm{i}^{2}=9.2 \\
(\mathrm{P}=0\end{array}$ & $\begin{array}{l}5, \mathrm{df}= \\
05)\end{array}$ & $4(P=C$ & $0.06) ; 1$ & $\left.\right|^{2}=57^{\circ}$ & & & $\begin{array}{ccccc}-20 & -10 & 0 & 10 & 20 \\
{[\text { experimental] }} & \text { [control] }\end{array}$ \\
\hline
\end{tabular}

Figure 8 Forest map for length of hospital stay for patients in both groups.

\begin{tabular}{|c|c|c|c|c|c|c|c|c|c|c|}
\hline Study or Subgroup & \multicolumn{2}{|c|}{ Experimental } & \multicolumn{2}{|c|}{ Control } & Weight & $\begin{array}{c}\text { Risk Ratio } \\
\text { M-H, Random, } 95 \% \mathrm{Cl}\end{array}$ & \multicolumn{4}{|c|}{$\begin{array}{c}\text { Risk Ratio } \\
\mathrm{M}-\mathrm{H}, \text { Random, } 95 \% \mathrm{Cl}\end{array}$} \\
\hline Esquinas 2018 & 50 & 86 & 44 & 70 & $21.2 \%$ & $0.92[0.72,1.19]$ & & & & \\
\hline Guillotreau 2009 & 13 & 38 & 25 & 30 & $17.4 \%$ & $0.41[0.26,0.66]$ & & & & \\
\hline Hemal 2007 & 6 & 30 & 10 & 35 & $10.5 \%$ & $0.70[0.29,1.70]$ & & & & \\
\hline Subirá-Ríos 2019 & 29 & 108 & 65 & 108 & $19.7 \%$ & $0.45[0.32,0.63]$ & & & & \\
\hline Yong 2017 & 10 & 29 & 26 & 28 & $16.6 \%$ & $0.37[0.22,0.62]$ & & & & \\
\hline Zheng 2012 & 12 & 45 & 19 & 65 & $14.7 \%$ & $0.91[0.49,1.69]$ & & & & \\
\hline Total $(95 \% \mathrm{Cl})$ & & 336 & & 336 & $100.0 \%$ & $0.58[0.39,0.85]$ & & & & \\
\hline Total events & 120 & & 189 & & & & & & & \\
\hline $\begin{array}{l}\text { Heterogeneity: } \mathrm{Tau}^{2}= \\
\text { Test for overall effect: }\end{array}$ & $\begin{array}{l}0.17 ; \mathrm{Chi}^{2}= \\
Z=2.77(\mathrm{P}\end{array}$ & $\begin{array}{l}21.70, \\
=0.006\end{array}$ & $d f=5(P$ & $=0.00$ & $06) ; 1^{2}=7$ & & 0.01 & $\begin{array}{c}0.1 \\
\text { [experimental] }\end{array}$ & ${ }_{\text {[control] }} 10$ & 100 \\
\hline
\end{tabular}

Figure 9 Forest map for the incidence of postoperative complications.

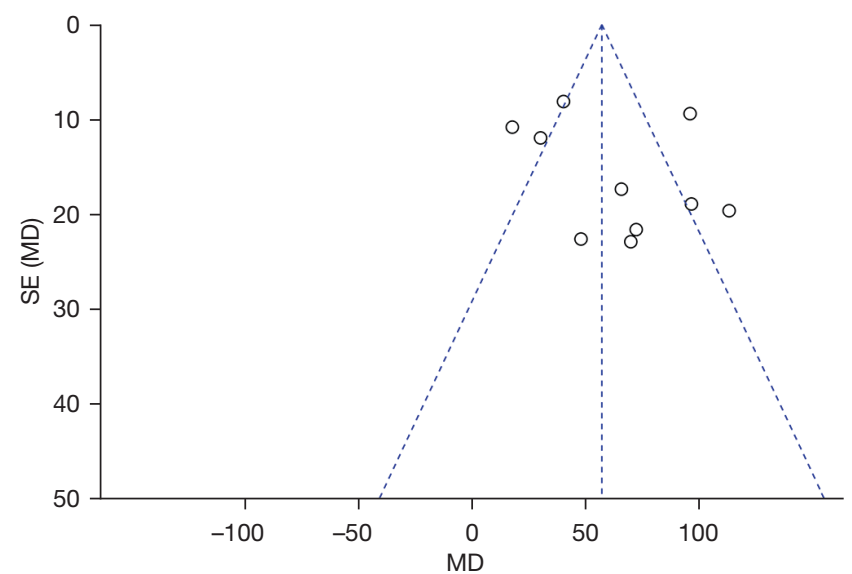

Figure 10 Funnel plot evaluation for publication bias of operation time. SE, standard error; MD, mean difference.

using the Review Manager 5.3 software. The results (Figures 10-15) revealed that scattered points representing the articles were located in the CI in terms of IBL, intraoperative BTR, and length of hospital stay, suggesting that the possibility of publication bias was lower. In the funnel charts of operation time, use of analgesics, and incidence of postoperative complications, some scattered points fell outside the CI, suggesting that a certain publication bias could be observed among the articles.

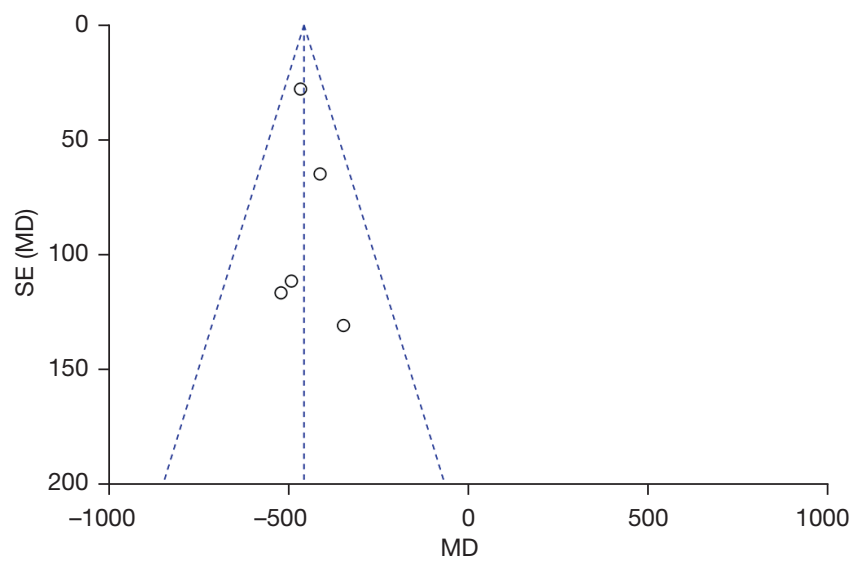

Figure 11 Funnel plot evaluation for publication bias of intraoperative blood loss.

\section{Discussion}

$\mathrm{BC}$ is the most common malignant urological tumor, which can be classified as MIBC or NMIBC according to the degree of lesion invasion. NMIB is limited to the bladder mucosa or submucosa, while MIBC extends beyond the bladder submucosa (32). Although MIBC accounts for only about $25 \%$ of BCs, most of them are high-grade urothelial carcinomas with high metastatic tendency, high risk of 


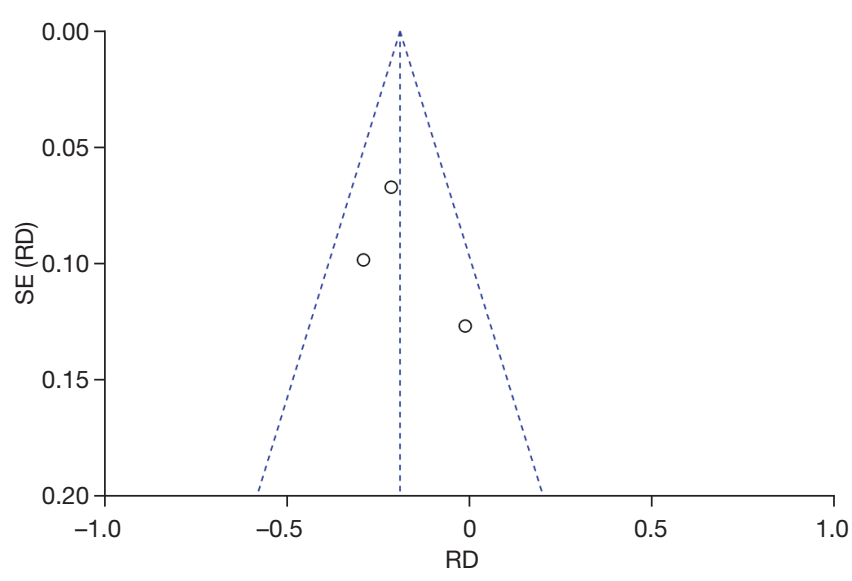

Figure 12 Funnel plot evaluation for publication bias of intraoperative blood transfusion rate. $\mathrm{RD}$, rate difference.

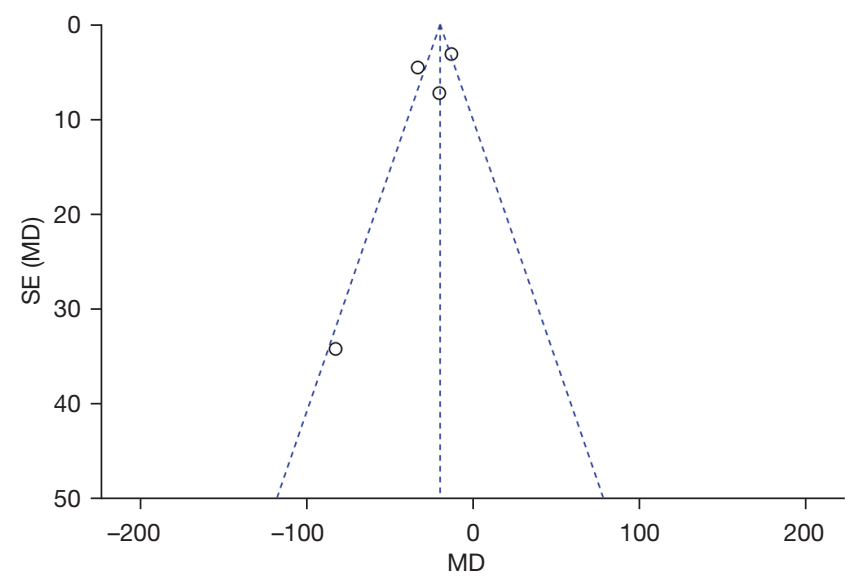

Figure 13 Funnel plot evaluation for publication bias of analgesics utilization.

lymph node metastasis, poor prognosis, and high mortality. It is impossible to cure patients with distant metastasis, and the median survival time is approximately $12-18$ months (33). $\mathrm{RC}$ combined with PLND is the standard procedure for the treatment of MIBC. With the development of minimally invasive techniques in recent years, LRC has gradually gained certain advantages over ORC in the treatment of breast cancer. LRC provides more accurate information on the tumor staging of breast cancer patients, and can also reduce the number of tumor cells and improve the survival rate of these patients. The operation time of ORC is short, but the length of hospital stay is longer, and there may be more complications (34). In contrast, LRC has less IBL, reduced length of hospital stay, and longer operation time. In addition, the minimally invasive treatment of the abdominal

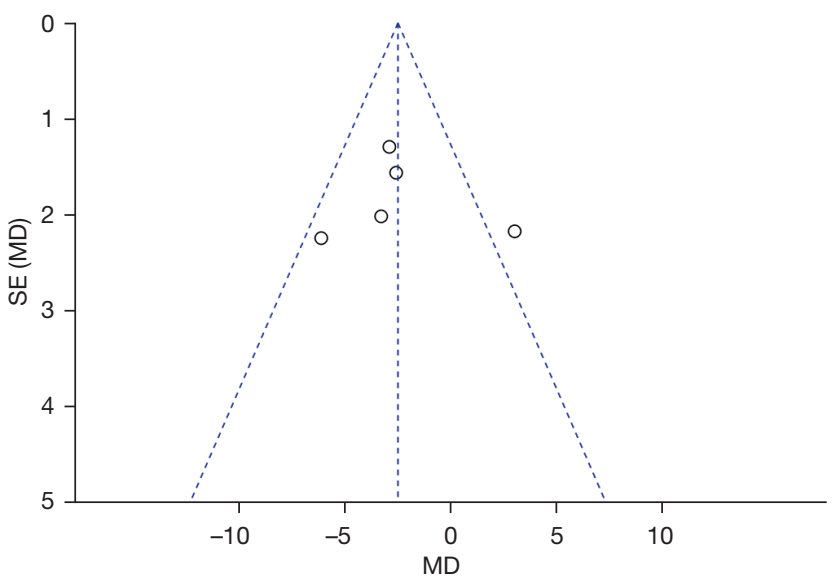

Figure 14 Funnel plot evaluation for publication bias of hospital stay length.

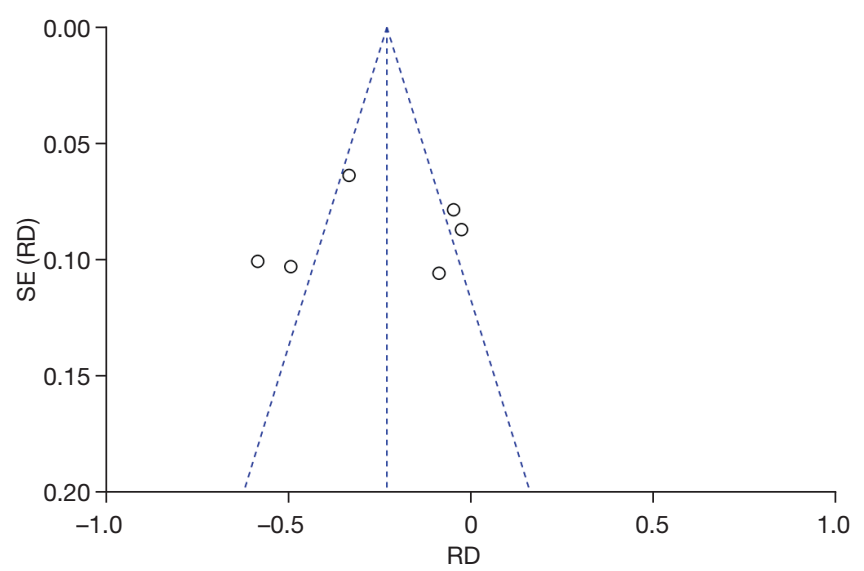

Figure 15 Funnel plot evaluation for publication bias of incidence of postoperative complications.

cavity utilized in LRC can relieve the postoperative pain of patients, thereby reducing the demand for opioids and helping the patient resume daily activities sooner (35).

In this study, we performed a meta-analysis to systematically evaluate the treatment effect of LRC on patients with BC. The 12 included articles covered 1,283 subjects. The results showed that LRC treatment of $\mathrm{BC}$ could effectively reduce the IBL and use of analgesics in patients, lower the intraoperative BTR and the probability of postoperative complications, but the operation time was longer. These results were similar to the findings of Aboumarzouk et al. However, it found that LRC treatment of BC failed to reduce the length of hospital stay in patients. A possible reason for this may be that the wide application of the current concept of accelerated rehabilitation surgery 
had in turn promoted the recovery of intestinal function after surgery. Furthermore, the difference between the two groups of patients in terms of postoperative recovery time was relatively small due to the adequate preparation of the intestinal tract before surgery.

Stopping urine can prolong the effect of carcinogens on the bladder. In life, people should develop a good habit of drinking more water and diligent urination. Stimulating foods play a key role in promoting the occurrence of diseases, so a suitable diet should be reasonably adjusted to avoid the occurrence of diseases. People who smoke and consume alcohol should also avoid these as much as possible. Furthermore, avoiding volatile emotions and promoting a relaxing mood can make the body and mind feel happy. Moreover, according to research, sweating through exercise can discharge acidified toxic substances in the body, leading to a healthier and more energetic body.

\section{Conclusions}

In this study, we conducted a systematic analysis and evaluation on the treatment effect of LRC on patients with BC. The results indicated that LRC could decrease the IBL and use of analgesics, lower the intraoperative BTR, and reduce the incidence of postoperative complications. The results of this study provide a reference for LRC treatment of BC. However, this study had some limitations that should be noted. Firstly, the number of included articles was small, which resulted in some indicators that lacked a certain degree of persuasiveness. Therefore, in future studies, more high-quality, multi-center, large-sample clinical controlled trials should be performed to further analyze the surgical effect of LRC in the treatment of BC, so as to provide an adequate basis for the treatment of $\mathrm{BC}$.

\section{Acknowledgments}

Funding: None.

\section{Footnote}

Reporting Checklist: The authors have completed the PRISMA reporting checklist. Available at https://tau. amegroups.com/article/view/10.21037/tau-21-1076/rc

Conflicts of Interest: All authors have completed the ICMJE uniform disclosure form (available at https://tau.amegroups. com/article/view/10.21037/tau-21-1076/coif). The authors have no conflicts of interest to declare.

Ethical Statement: The authors are accountable for all aspects of the work in ensuring that questions related to the accuracy or integrity of any part of the work are appropriately investigated and resolved.

Open Access Statement: This is an Open Access article distributed in accordance with the Creative Commons Attribution-NonCommercial-NoDerivs 4.0 International License (CC BY-NC-ND 4.0), which permits the noncommercial replication and distribution of the article with the strict proviso that no changes or edits are made and the original work is properly cited (including links to both the formal publication through the relevant DOI and the license). See: https://creativecommons.org/licenses/by-nc-nd/4.0/.

\section{References}

1. Martinez Rodriguez RH, Buisan Rueda O, Ibarz L. Bladder cancer: Present and future. Med Clin (Barc) 2017;149:449-55.

2. DeGeorge KC, Holt HR, Hodges SC. Bladder Cancer: Diagnosis and Treatment. Am Fam Physician 2017;96:507-14.

3. Cao R, Yuan L, Ma B, et al. An EMT-related gene signature for the prognosis of human bladder cancer. J Cell Mol Med 2020;24:605-17.

4. Lenis AT, Lec PM, Chamie K, et al. Bladder Cancer: A Review. JAMA 2020;324:1980-91.

5. Dobruch J, Daneshmand S, Fisch M, et al. Gender and Bladder Cancer: A Collaborative Review of Etiology, Biology, and Outcomes. Eur Urol 2016;69:300-10.

6. Farling KB. Bladder cancer: Risk factors, diagnosis, and management. Nurse Pract 2017;42:26-33.

7. Cumberbatch MGK, Jubber I, Black PC, et al. Epidemiology of Bladder Cancer: A Systematic Review and Contemporary Update of Risk Factors in 2018. Eur Urol 2018;74:784-95.

8. Wang G, McKenney JK. Urinary Bladder Pathology: World Health Organization Classification and American Joint Committee on Cancer Staging Update. Arch Pathol Lab Med 2019;143:571-7.

9. Pham A, Ballas LK. Trimodality therapy for bladder cancer: modern management and future directions. Curr Opin Urol 2019;29:210-5.

10. Song YP, McWilliam A, Hoskin PJ, et al. Organ preservation in bladder cancer: an opportunity for truly 
personalized treatment. Nat Rev Urol 2019;16:511-22.

11. Yin M, Joshi M, Meijer RP, et al. Neoadjuvant Chemotherapy for Muscle-Invasive Bladder Cancer: A Systematic Review and Two-Step Meta-Analysis. Oncologist 2016;21:708-15.

12. Patel VG, Oh WK, Galsky MD. Treatment of muscleinvasive and advanced bladder cancer in 2020. CA Cancer J Clin 2020;70:404-23.

13. Perera M, McGrath S, Sengupta S, et al. Pelvic lymph node dissection during radical cystectomy for muscleinvasive bladder cancer. Nat Rev Urol 2018;15:686-92.

14. Fransen van de Putte EE, Pos F, Doodeman B, et al. Concurrent Radiotherapy and Panitumumab after Lymph Node Dissection and Induction Chemotherapy for Invasive Bladder Cancer. J Urol 2019;201:478-85.

15. Gschwend JE, Heck MM, Lehmann J, et al. Extended Versus Limited Lymph Node Dissection in Bladder Cancer Patients Undergoing Radical Cystectomy: Survival Results from a Prospective, Randomized Trial. Eur Urol 2019;75:604-11.

16. Parekh DJ, Reis IM, Castle EP, et al. Robot-assisted radical cystectomy versus open radical cystectomy in patients with bladder cancer (RAZOR): an open-label, randomised, phase 3, non-inferiority trial. Lancet 2018;391:2525-36.

17. Su S, Gu L, Ma X, et al. Comparison of Laparoscopic and Robot-assisted Radical Cystectomy for Bladder Cancer: Perioperative and Oncologic Outcomes. Clin Genitourin Cancer 2019;17:e1048-53.

18. Kanno T, Ito K, Sawada A, et al. Complications and reoperations after laparoscopic radical cystectomy in a Japanese multicenter cohort. Int J Urol 2019;26:493-8.

19. Aboumarzouk OM, Hughes O, Narahari K, et al. Safety and feasibility of laparoscopic radical cystectomy for the treatment of bladder cancer. J Endourol 2013;27:1083-95.

20. Basillote JB, Abdelshehid C, Ahlering TE, et al. Laparoscopic assisted radical cystectomy with ileal neobladder: a comparison with the open approach. J Urol 2004;172:489-93.

21. Hemal AK, Kolla SB. Comparison of laparoscopic and open radical cystoprostatectomy for localized bladder cancer with 3-year oncological followup: a single surgeon experience. J Urol 2007;178:2340-3.

22. Guillotreau J, Gamé X, Mouzin M, et al. Radical cystectomy for bladder cancer: morbidity of laparoscopic versus open surgery. J Urol 2009;181:554-9; discussion 559.

23. Ha US, Kim SI, Kim SJ, et al. Laparoscopic versus open radical cystectomy for the management of bladder cancer: mid-term oncological outcome. Int J Urol 2010;17:55-61.

24. Pruthi RS, Nix J, McRackan D, et al. Robotic-assisted laparoscopic intracorporeal urinary diversion. Eur Urol
2010;57:1013-21.

25. Zheng W, Li X, Song G, et al. Comparison of laparoscopic and open cystectomy for bladder cancer: a single center of 110 cases report. Transl Androl Urol 2012;1:4-8.

26. Pyun JH, Kim HK, Cho S, et al. Robot-Assisted Radical Cystectomy with Total Intracorporeal Urinary Diversion: Comparative Analysis with Extracorporeal Urinary Diversion. J Laparoendosc Adv Surg Tech A 2016;26:349-55.

27. Yong C, Daihui C, Bo Z. Laparoscopic versus open radical cystectomy for patients with bladder cancer over 75-yearold: a prospective randomized controlled trial. Oncotarget 2017;8:26565-72.

28. Esquinas C, Alonso JM, Mateo E, et al. Prospective study comparing laparoscopic and open radical cystectomy: Surgical and oncological results. Actas Urol Esp (Engl Ed) 2018;42:94-102.

29. Lenfant L, Verhoest G, Campi R, et al. Perioperative outcomes and complications of intracorporeal vs extracorporeal urinary diversion after robot-assisted radical cystectomy for bladder cancer: a real-life, multiinstitutional french study. World J Urol 2018;36:1711-8.

30. Subirá-Ríos D, Herranz-Amo F, Moralejo-Gárate M, et al. Influence of the laparoscopic approach on cancer-specific mortality of patients with stage pt3-4 bladder cancer treated with cystectomy. Actas Urol Esp (Engl Ed) 2019;43:71-6.

31. Huang H, Yan B, Hao H, et al. Laparoscopic versus open radical cystectomy in 607 patients with bladder cancer: Comparative survival analysis. Int J Urol 2021;28:673-80.

32. Pecoraro M, Takeuchi M, Vargas HA, et al. Overview of VI-RADS in Bladder Cancer. AJR Am J Roentgenol 2020;214:1259-68.

33. Audenet F, Attalla K, Sfakianos JP. The evolution of bladder cancer genomics: What have we learned and how can we use it? Urol Oncol 2018;36:313-20.

34. Michels CTJ, Wijburg CJ, Leijte E, et al. A costeffectiveness modeling study of robot-assisted (RARC) versus open radical cystectomy (ORC) for bladder cancer to inform future research. Eur Urol Focus 2019;5:1058-65.

35. Nakane K, Enomoto T, Hishida S, et al. The Utility and Efficacy of Laparoscopic Radical Cystectomy in Patients with Muscle-Invasive Bladder Cancer at a Single Institution. Urol Int 2020;104:573-9.

Cite this article as: Zhu J, Lu Z, Chen W, Ke M, Cai X. Systematic review and meta-analysis on laparoscopic cystectomy in bladder cancer. Transl Androl Urol 2022;11(1):67-78. doi: 10.21037/tau-21-1076 